\title{
Chatter identification in turning process based on vibration analysis using Hilbert- Huang transform
}

\author{
A. Susanto ${ }^{1,2, *}$, K. Yamada 2 , R. Tanaka ${ }^{2}$, Y. A. Handoko ${ }^{3}$ and M. F. Subhan ${ }^{4}$ \\ ${ }^{1}$ Department of Railway Engineering, State Polytechnic of Madiun, Serayu No. 84, 63131, Madiun, Indonesia, \\ Phone: (0351) 452970; Fax: (0351) 492960 \\ ${ }^{2}$ Graduate School of Engineering, Hiroshima University, Higashi-Hiroshima, 739-8527, Japan \\ ${ }^{3}$ Department of Mechanical \& Aerospace Engineering, Bandung Institute of Tech., Bandung, Indonesia. Division of Rolling Stock, INKA, Indonesia \\ ${ }^{4}$ State Polytechnic of Malang, Soekarno Hatta No.9, 64151, Malang, Indonesia
}

\begin{abstract}
In machining process, the increasing cutting depth is aimed to accelerate machining operations in a short time. However, the increasing cutting depth can cause chatter vibration at any time. Chatter can accelerate tool wear and lead to poor machined surface. This paper studied the application of Hilbert-Huang transform (HHT) to analyse chatter caused by the increasing cutting depth during operation. Chatter vibration is typical of non-stationary and non-linear vibration signals, therefore it should be analysed by appropriate signal processing; HHT. In this research, initially "hammering tests" were conducted to observe dynamic modal parameters of cutting system; modal mass, damping ratio, and stiffness. Then stability lobe chart was generated based on those dynamic modal parameters to determine cutting parameters. Second, turning tests were conducted and then vibrations obtained in turning tests were analysed using HHT for chatter detection. The results were then compared by conventional signal processing; short-time Fourier (STFT) transforms. The results show that the empirical mode decomposition (EMD) of HHT process separated complex vibrations into simple components and isolated chatter from the others. The chatter was isolated in the first IMF. Therefore, chatter can be identified by EMD process. In the spectrum analysis, HHT spectra showed its superiority over STFT spectra. HHT spectra provided high time resolution and high frequency resolution both rather than STFT spectra that provided blurry and blocked spectra. The implication is that HHT can be applied to monitor the machining process.
\end{abstract}

ARTICLE HISTORY

Revised: $15^{\text {th }}$ Nov 2019

Accepted: $23^{\text {rd }}$ Apr 2020

\section{KEYWORDS}

Chatter;

turning;

energy-time-frequency; Hilbert-Huang transform; short-time Fourier transform.

\section{INTRODUCTION}

The turning process is widely applied in industry for machining the metal components in the final step of manufactures [1]. In this step, both high accuracy and perfect surface finish of the final product are required. However, the turning operation of metals is often messed up by a messy vibration which is well-known as chatter, which is caused by relative contacting between tool and workpiece. Chatter vibration can lead to some negative effects, such as; make poor machined surface, accelerate tool wear and reduce machine tool life [2,3]. Therefore, machining process monitoring is absolutely needed in order to keep away from the chatter vibration.

One of the best ways for chatter vibration identification is based on vibration analysis using a proper signal processing tool. In the vibration analysis to chatter identification, frequency-domain analysis obtained by fast Fourier transform (FFT) is commonly used [4,5]. Ma et al. [6] proposed method an active sliding mode controller for chatter vibration suppression in turning process. They confirmed the proposed method experimentally in turning tests and employed FFT to analyse acquired vibration signals in tests. Although FFT-based method is widely used as a powerful of signal processing tool for turning condition monitoring, but the drawback of this method is that FFT cannot be applied for nonstationary signals analysis. In fact, the signals detected during machining are sometimes non-stationary. FFT is unable to detect the frequency changes as it averages the frequency composition over the duration of the signal with a fixed resolution of the entire frequency spectrum [7].

To address this issue, short-time Fourier (STFT), Wavelet (WT), Stockwell (ST) transforms were utilized for processing the signals in time-frequency domain analysis (TFA). STFT was used for analysing vibrations acquired in milling of a thin-walled cantilever and ring-type casing [8] and in parallel turning for chatter detection [9]. ST was also employed for analysing vibrations obtained in turning by Tansel et al. [10]. On the other hand, the torque and forces signals were processed by using WT for estimating drill bit wear in [11].

The researchers who were interested in signal processing mentioned the shortcoming of the above TFA techniques that they are based on FFT theory. For example, the disadvantage of the STFT was a trade-off between frequency resolution and time range [12], i.e. higher the time resolution, lower the frequency resolution is, and vice versa. For ST, 
the basic theory of this method is based on the FFT [10], so that it has same weakness. And in the WT, the suitable wavelet base function and decomposition level are difficult to be determined which in turn can affect the analysis results significantly [13]. Besides, the above mentioned TFA is appropriate for analysis stationary and linear signals. However, vibration signals obtained in machining indeed nonlinear and non-stationary [14]. Therefore, they are actually hampered for of analysing vibrations signals obtained in machining process.

Hilbert-Huang transform (HHT) is one of the powerful TFA recently which this method is not hampered to analyse the nonlinear and non-stationary of vibration [15]. HHT is also an appropriate signal processing tool for feature extraction to get correct information about chatter vibration. This method has been a few applied for chatter monitoring in milling [16]-[18]. In this works, they utilized HHT for monitoring several milling conditions; in dry cutting, wet cutting, and bumping milling. HHT also used for monitoring the end-mill condition in milling [19], and drilling [20].

This paper presents the application of HHT to analyse chatter vibration caused by the increasing cutting depth during operation. Because chatter vibration is typical of non-linear and non-stationary vibration signals, therefore it should be analysed by appropriate signal processing. In machining process, the increasing cutting depth is aimed to accelerate machining operation in a short time. However, during this period some frequencies may be excited, and some machine initial failure modes may show up from the transient signals. Therefore, it is crucial to monitor the machining condition properly in these periods to ensure the integrity of the machining process.

\section{METHODS AND MATERIALS}

\section{Dynamic Model in Turning}

Figure 1 is a dynamic model in thin-tubular turning which is composed of dynamic modal parameters; mass $m$, damping $c$, and stiffness $k$. This model can vibrate caused by cutting force $F(t)$ acting during material removal which in turn can produce a wavy profile on the workpiece. When the workpiece rotates for the next revolution, the tool encounters wavy surface left in previous rotation, and then produces fluctuated uncut chip thickness at any time. The uncut chip thickness is dependent on both the wavy profile (vibration mark) left by previous and present vibration. The vibration subsequently determines whether the turning operation is stable or unstable (chatter occurs). Here, the subscripts of $x$ and $y$ indicate the direction of considered vibration modes.

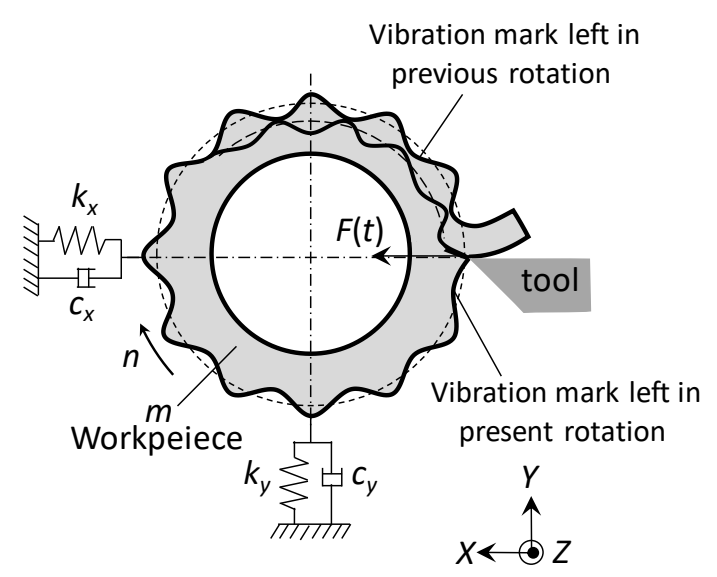

Figure 1. Dynamic model in turning of thin-tubular workpiece.

The equation of motion for vibration model shown in Figure 1 can be expressed as follow:

$$
[M]\left\{\begin{array}{c}
\ddot{x} \\
\ddot{y}
\end{array}\right\}(t)+[C]\left\{\begin{array}{l}
\dot{x} \\
\dot{y}
\end{array}\right\}(t)+[K]\left\{\begin{array}{l}
x \\
y
\end{array}\right\}(t)=F(t)
$$

where $[M],[C]$, and $[K]$ are mass, damping and stiffness matrices and $\ddot{x}, \ddot{y}$ are acceleration that can be represented as velocity $(\dot{x}, \dot{y})$ and displacement $(x, y)$. Besides, the uncut chip thickness is expressed as follows [21]:

$$
h(t)=h_{o}(t)-\left\{\begin{array}{l}
x(t)-x(t-\tau) \\
y(t)-y(t-\tau)
\end{array}\right\}
$$

in the Laplace domain, the uncut chip thickness is expressed as: 


$$
h(s)=h_{o}(s)+\left(e^{-s \tau}-1\right)\left\{\begin{array}{l}
x(s) \\
y(s)
\end{array}\right\}
$$

where $h_{0}$ is controlled uncut chip thickness and $\tau$ is a spindle revolution period. Besides, the cutting force acting on the operation is expressed as;

$$
F(s)=A K_{s} h(s)
$$

where $A$ is width of cut and $K_{s}$ is cutting force coefficient. Equation (4) can be represented as the frequency response function $[G(s)]$ which is relationship between the displacement and force as follow;

$$
\left\{\begin{array}{l}
x(s) \\
y(s)
\end{array}\right\}=[G(s)] A K_{s} h(s)
$$

Substituting (5) into (3) yields:

$$
h(s)=h_{o}(s)+\left(e^{-s \tau}-1\right)[G(s)] A K_{s} h(s)
$$

From Eq. (6), the ratio between controlled chip thickness to uncut chip thickness can be achieved:

$$
\frac{h_{o}(s)}{h(s)}=\frac{1}{1-\left(e^{-s \tau}-1\right)[G(s)] A K_{s}}
$$

The stability limit at the chatter vibration frequency $\omega_{c}$ can be determined by:

$$
1-\left(e^{-s \tau}-1\right)\left[G\left(j \omega_{c}\right)\right] A_{a \lim } K_{s}=0
$$

where $A_{a \text { lim }}$ is limiting depth of cut for chatter free machining and $G\left(j \omega_{c}\right)$ is the chatter's frequency response function. This frequency response function can be expressed to other expression with considering the frequency ratio $r=\omega / \omega_{c}$ and damping ratio $\zeta$ as follows:

$$
G\left(j \omega_{c}\right)=\frac{1}{k}\left(\frac{\left(1-r^{2}\right)-i 2 \zeta r}{\left(1-r^{2}\right)^{2}+(2 \zeta r)^{2}}\right)
$$

Equation (9) shows a complex equation that can be expressed into real and imaginary functions as follows:

$$
\begin{gathered}
\operatorname{Re}\left[G\left(j \omega_{c}\right)\right]=\frac{1}{k}\left(\frac{1-r^{2}}{\left(1-r^{2}\right)^{2}+(2 \zeta r)^{2}}\right) \\
\operatorname{Im}\left[G\left(j \omega_{c}\right)\right]=\frac{1}{k}\left(\frac{-2 \zeta r}{\left(1-r^{2}\right)^{2}+(2 \zeta r)^{2}}\right)
\end{gathered}
$$

The frequency response functions $G\left(j \omega_{c}\right)$ in Eq. (8) determine the stability limit of depth of cut $A_{a \text { lim }}$ and phase angle $\varepsilon$ as follows:

$$
\begin{gathered}
A_{a \lim }=-\frac{1}{2 K_{s} \operatorname{Re}\left[G\left(j \omega_{c}\right)\right]} \\
\varepsilon=\pi-2 \tan ^{-1}\left(\frac{\operatorname{Re}\left[G\left(j \omega_{c}\right)\right]}{\operatorname{Im}\left[G\left(j \omega_{c}\right)\right]}\right)
\end{gathered}
$$


Stability lobes chart (SLD) at the chatter vibration frequency $\omega_{c}$ can be generated using Eqs. (12) and (13) and calculates the spindle speed ${ }_{n=} \frac{60 \omega_{c}}{l b+\varepsilon}$, with $l_{b}$ is integer number of the lobes.

\section{Hilbert-Huang Transform}

Hilbert-Huang transform (HHT) contains two consecutive procedures and Empirical mode decomposition (EMD) is the first procedure. By using (EMD), the raw data can be separated into a series of components, and they are called intrinsic mode functions (IMFs). The EMD procedure is summarized in the following algorithm [16,22]:

Step 1: The simulation signal $x(t)=\sin \left(\frac{\pi(t)}{65}\right) \sin \left(\frac{\pi(t)}{65}\right)$ is considered as the raw data.

Step 2: The $x(t)$ should be checked before continuing to next step to ensure whether the $x(t)$ is monotonic data or not. Monotonic data means no IMF can be resulted, otherwise if the data non-monotonic, the process will continue to next step. Let us suppose again that the raw data is non-monotonic.

Step 3: All local maxima and minima of the signal are identified, and then create upper and lower curves using cubic spline lines.

Step 4: Determine the mean $m(t)$ of upper and lower envelopes. Steps 1-4 are illustrated in Figure 2(a).

Step 5: Finding proto IMF, $x(t)-m(t)=h(t)$. The $h(t)$ is shown in Figure 2(b).

To get an IMF $c_{j}(t)$, following sifting process is performed;

$x(t)-m_{1,1}(t)=h_{1,1}(t)$;

$h_{1,1}(t)-m_{1,2}(t)=h_{1,2}(t)$;

$h_{1,2}(t)-m_{1,3}(t)=h_{1,3}(t)$;

...

$h_{1, k-1}(t)-m_{1, k}(t)=h_{1, k}(t)$;

$\Rightarrow h_{1, k}(t)=c_{1}(t)$,

where the indices indicate the iteration of the same step and $c_{1}(t)$ is the first IMF.

Step 6: Determine the residue by $r_{1}(t)=x(t)-c_{1}(t)$. By repeating the steps 2-5 and $r_{1}(t)$ is treated as the data, so that the second $\mathrm{IMF} c_{2}(t)$ can be derived. The steps are repeated $n_{k}$ times and monotonic function is resulted;

$x(t)-c_{1}(t)=r_{1}(t)$

$r_{1}(t)-c_{2}(t)=r_{2}(t)$

...

$r_{n-1}(t)-c_{j}(t)=r_{n}(t)$

Step 7: The decomposition process will stop when $r_{n}(t)$ becomes a monotonic function.

The decomposition of the raw signal $x(t)$ into a set of IMF components $\left(c_{j}(t)\right)$ and a monotonic residue $\left(r_{n k}\right)$ can be achieved as:

$$
x(t)=\sum_{j=1}^{N k} c_{j}(t)+r_{n k}(t)
$$




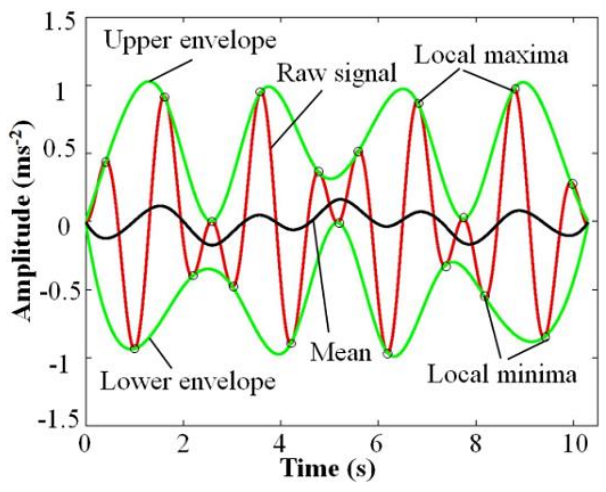

(a) Raw data, local maxima and minima, upper and lower envelopes, mean of envelope

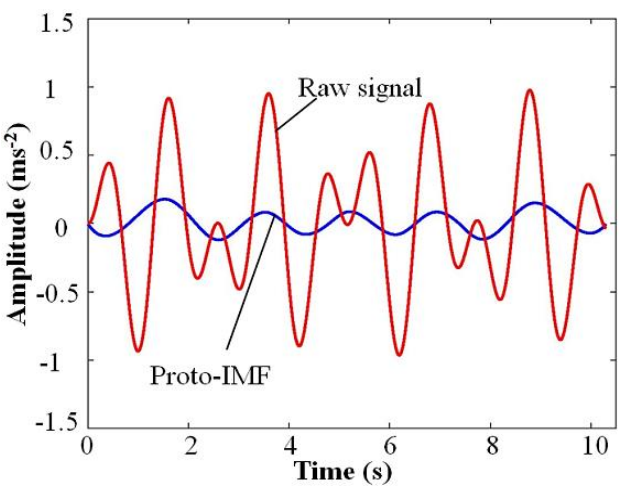

(b) Raw data and proto-IMF

Figure 2. Sifting process

The second step of HHT is applying Hilbert transform to all IMF components for generating an energy-time-frequency distribution which is presented in HHT spectrum. For given data $x(t)$, the Hilbert transform can be expressed as [22]:

$$
\left.x(t)=\sum_{j=1}^{N k} a_{j}(t) \exp \left(i \int \omega_{j}(t) d t\right)\right)
$$

where $a_{j}(t)$ and $\omega_{j}(t)$ are the instantaneous amplitude and instantaneous frequency.

\section{Workpiece and Cutting Tool}

Machine tool used in turning tests was ANNYANG lathe machine and the work-material was AISI 1045 steel. This type of material is widely applied in railway components or other vehicles; such as for axles, connecting rods, bolts, pins, rolls, spindles, ratchets, crankshafts, torsion bars, sockets, worms, light gears, and guide rods. The chemical composition of the AISI 1045 steel was 97.2 Fe, 0.46 C, 0.24 Si, 0.45 Mn, 0.015 Cr, 0.008 P, 0.003 S, 0.01 Co, and 0.01 Ni [23]. The dimension of the workpiece used in the experimental test is shown in Figure 3. As shown in the figure, the workpiece contains solid and thin-tubular structures with $200 \mathrm{~mm}$ in total length; $50 \mathrm{~mm}$ is solid, and $150 \mathrm{~mm}$ is a thin-tubular structure. The outer diameter is $38 \mathrm{~mm}$ and the inner diameter $d_{1}$ is $35 \mathrm{~mm}$ with the wall-thickness $\mathrm{t}=3 \mathrm{~mm}$. As shown in Figure 3, workpiece is clamped on the solid structure using three-jaw chuck and thin-tubular structure is free clamped. The workpieces were machined using a carbide tool in straight turning.

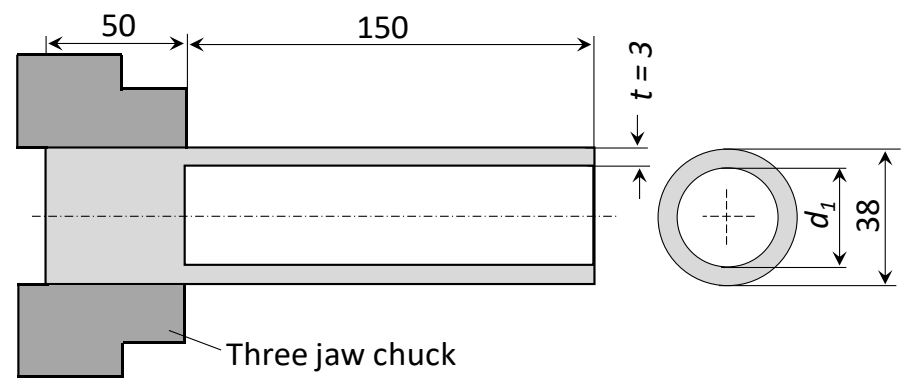

Figure 3. Workpiece dimension (unit is in $\mathrm{mm}$ ).

\section{Dynamic Cutting System Identification}

Stability lobe chart as derived in the previous section is generated first to determine cutting parameters, namely; a pair of cutting depth and spindle rotation. To this purpose, the impact test is needed to measure frequency response function (FRF) and then the FRF is extracted by experimental modal analysis (EMA) technique to get the dynamic parameters; modal mass $m$, damping ratio $\zeta$ and stiffness $k$ [24].

Figure 4 shows the impact test setup in turning schematically. Here, dynamic behavior of the workpiece was measured because it was the most flexible in mechanical structure of this study. Figure 4(a) shows the apparatus used in the test. As shown on the figure, the workpiece is excited using a Dytran hammer. The impulse force of hammer is measured by force transducer mounted in the tip of hammer. Besides, response signal is measured by B\&K accelerometer sensor mounted in the workpiece. Both of impulse force of hammer and response signal are acquired using PICO oscilloscope. The 
personal computer with Pico-scope shows the waveform of those vibrations, which were collected as the data. The impact method is conducted as in Figure 4(b) and 4(c) to get direct FRF; $G_{x x}(\omega)$ and $G_{y y}(\omega)$.

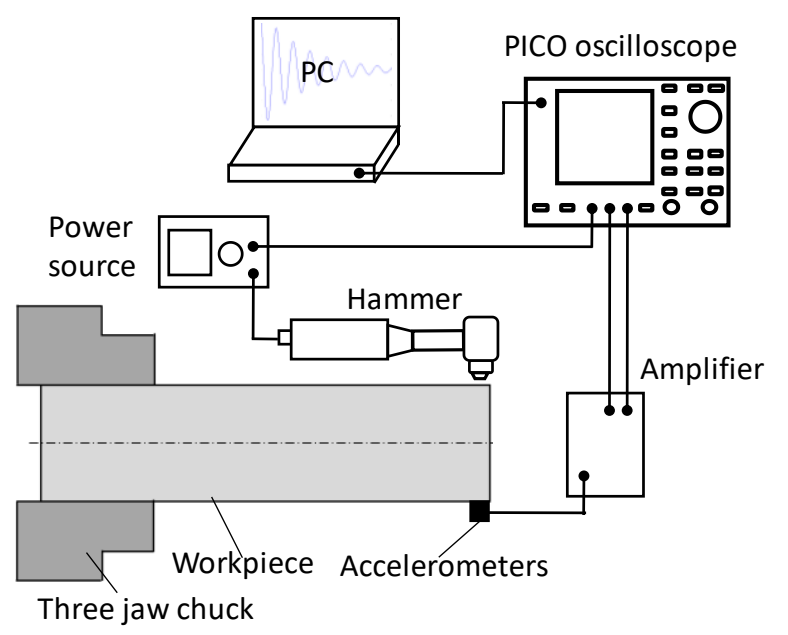

(a) Apparatus used in experimental impact test

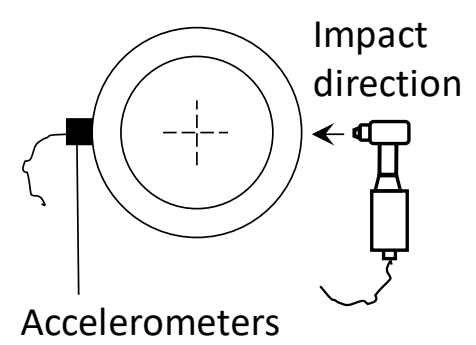

(b) Impact method to get direct $\operatorname{FRF}\left(G_{x x}\right)$
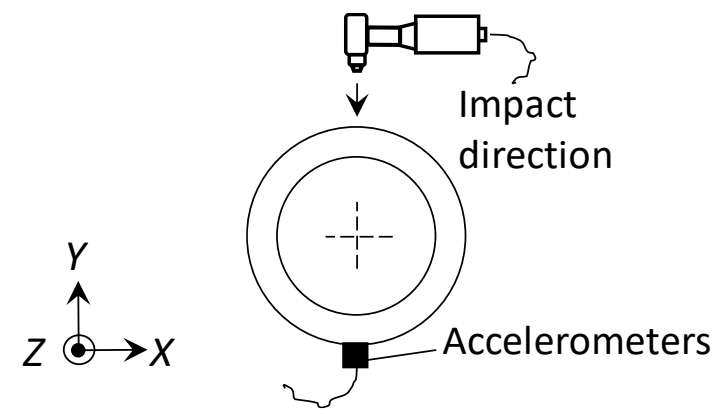

Figure 4. Hammering test setup.

Measured FRFs are shown in Figure 5. Figure 5(a) and 5(b) are real and imaginary parts of FRF, respectively. Black curves present $G_{x x}$ and red curves present $G_{y y}$. As shown in the figure, the peak of imaginary part of FRF contains natural frequency $\left(f_{n x x}\right)$ that corresponds to compliance value $\left(A_{x x}\right)$, and for real part of FRF contains two specific frequencies ( $f_{x x}$ and $f_{-x x}$ ) correspond to highest peaks. According to these values, the dynamic parameters can be determined using EMA technique and the result is shown in Table 1.

Following, SLD was generated and the result is shown in Figure 6. The SLD was generated using the dynamic parameters in Table 1 and cutting force coefficient $K_{s}=2600 \mathrm{~N} / \mathrm{m}^{2}$ [24]. In our analytical SLD, 7 lobes $\left(l_{b}=0 \ldots 6\right)$ are obtained for rotational speed of spindle from 100 to $1000 \mathrm{~min}^{-1}$. In SLD, any pair of spindle rotation and cutting depth that appears above of the lobe indicates unstable cutting, while any pair below of the lobe indicates stable cutting. 

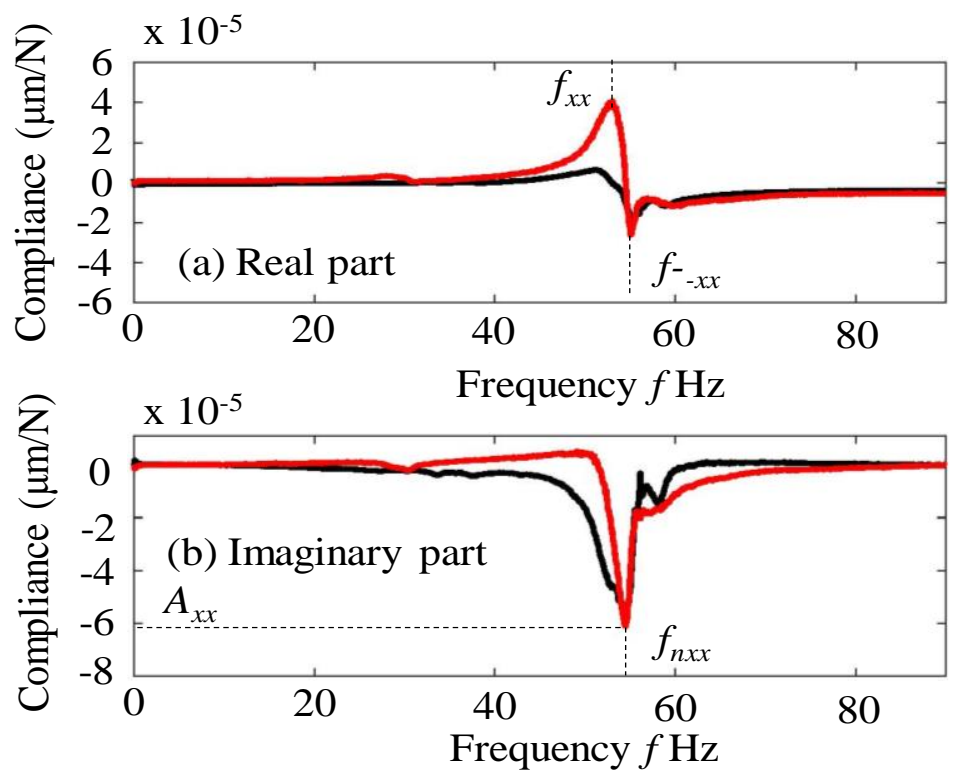

Figure 5. Measured FRFs by hammering test: (a) real part of FRF, and (b) imaginary part of FRF. Black and red curves indicate $G_{x x}$ and $G_{y y}$, respectively.

Table 1. Dynamic modal parameters of thin-tubular workpice.

\begin{tabular}{ccccc}
\hline $\begin{array}{c}\text { Type of } \\
\text { FRF }\end{array}$ & $\begin{array}{c}\text { Natural frequency } \\
f_{n}(\mathrm{~Hz})\end{array}$ & $\begin{array}{c}\text { Damping ratio } \\
\zeta(\%)\end{array}$ & $\begin{array}{c}\text { Stiffness } \\
k(\mathrm{~N} / \mathrm{m})\end{array}$ & $\begin{array}{c}\text { Mass } \\
m(\mathrm{~kg})\end{array}$ \\
\hline$G_{x x}(\omega)$ & 55 & 1.25 & $2.5 \times 10^{6}$ & 0.046 \\
$G_{y y}(\omega)$ & 54 & 1.64 & $2.6 \times 10^{6}$ & 0.339 \\
\hline
\end{tabular}

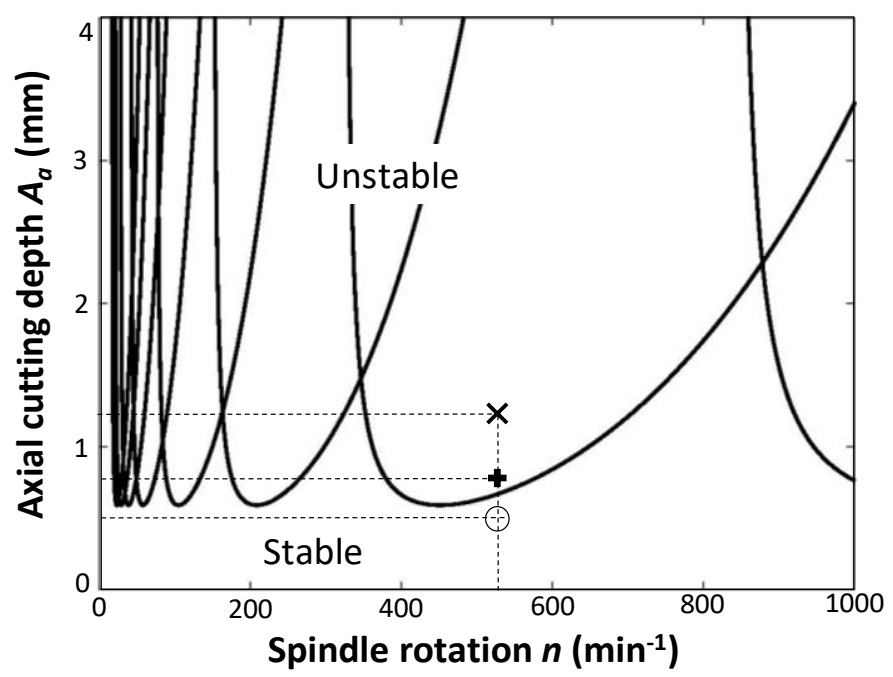

Figure 6. Stability lobe diagram for determining cutting parameter.

\section{Experimental Turning Tests}

In experimental turning tests, the cutting parameters were determined by SLDs shown in Figure 6. The cutting parameters are shown in Table 2 in detail. Besides, Figure 7 shows the experimental turning test setup, which the cutting vibrations were measured by accelerometer sensor, and then acquired by a data storage system; PICO oscilloscope. 
Table 2. Cutting condition for observing chatter in turning tests.

\begin{tabular}{ccccc}
\hline No. & $\begin{array}{c}\text { Feed rate } \\
V_{f}(\mathrm{~mm} / \mathrm{rev})\end{array}$ & $\begin{array}{c}\text { Spindle rotation } \\
n\left(\mathrm{~min}^{-1}\right)\end{array}$ & $\begin{array}{c}\text { Axial cutting depth } \\
A_{a}(\mathrm{~mm})\end{array}$ & Cutting states \\
\hline 1 & & & 0.5 & Stable \\
2 & 0.06 & 550 & 0.8 & Slight chatter \\
3 & & & 1.2 & Severe chatter \\
\hline
\end{tabular}

Three jaw chuck

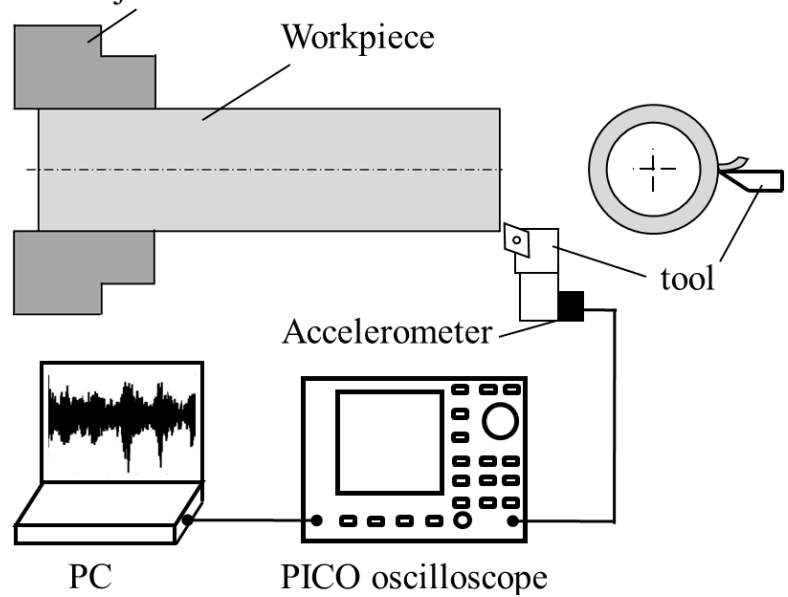

Figure 7. Setup for experimental turning tests.

\section{RESULTS AND DISCUSSION}

\section{Chatter Identification}

Figures 8 shows vibrations acquired in turning tests under cutting conditions given in Table 2. As can be seen from the figures, the vibration amplitudes are varying over the cutting period. Figure 8(a) is vibration acquired in stable operation, which its amplitude is smaller than others and smooth during the cutting period. As expected, the test result in this figure agrees with the analytical prediction using the stability lobe diagram shown in Figure 6 . At the cutting combination of spindle speed $n=550 \mathrm{~min}^{-1}$ with cutting depth $A_{a}=0.8 \mathrm{~mm}$, the cutting process is close to unstable. See Figure 8(b); the amplitude of vibration is growing up significantly with time and the becoming larger than ones in Figure 8(a). Less favourable of cutting combination are spindle speed $n=550 \mathrm{~min}^{-1}$ with cutting depth $A_{a}=1.2 \mathrm{~mm}$, the severe chatter vibration is observed in Figure 8(c). As can be seen, not only the vibration signal amplitude is chaotic and growing with time, but nonlinearity of vibration is also observed; approximately $11 \mathrm{~s}, 16 \mathrm{~s}$, and $20 \mathrm{~s}$.

This chatter was imprinted on the surface of the workpiece are shown in Figure 9(b). Besides, the machined surfaces obtained in the stable process in Figure 9(a). It has been observed during the turning operation that the cutting was generally stable in the $A_{a}=0.5 \mathrm{~mm}, n=550 \mathrm{rpm}$ combination; when the cutting depth is increased to accelerate machining operation in a short time, severe chatter vibration occurred leaving chatter marks on the machined surface. This experimental observation is in good agreement with the SLD. Furthermore, FFT, STFT, and HHT were applied to analyse the vibrations in Figure 8 for chatter identification in the next section.

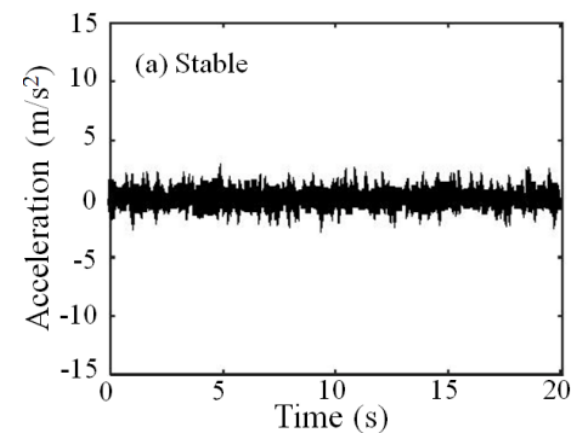

$A_{a}=0.5 \mathrm{~mm}, n=550 \mathrm{rpm}$

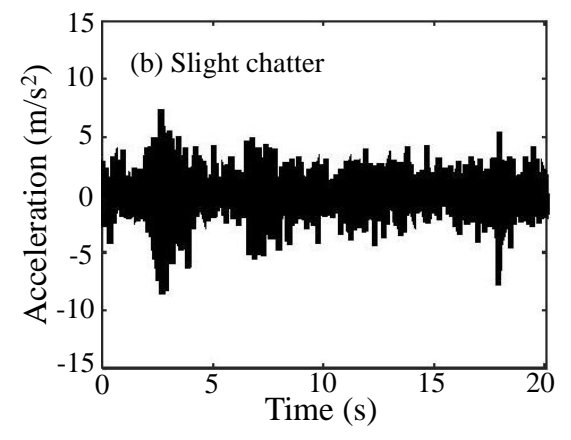

$A_{a}=0.8 \mathrm{~mm}, n=550 \mathrm{rpm}$ 


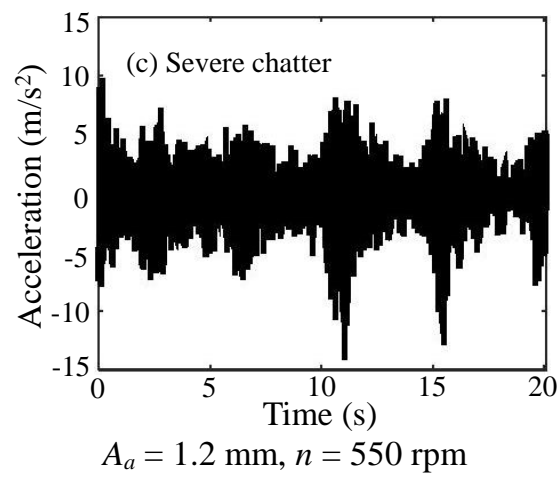

Figure 8. Effect of different cutting depths on vibrations on turning of thin-tubular workpieces.
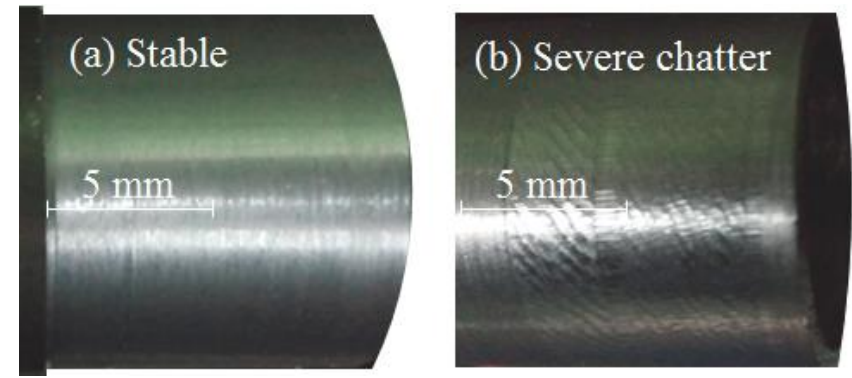

Figure 9. Machined surfaces obtained in turning of thin-tubular workpieces.

\section{Vibration Analysis using FFT}

Fast Fourier transform (FFT) was used to observe the frequency contents when the chatter occurs. The frequency spectrum obtained by FFT is shown in Figure 10. According to these figures, several frequencies appear in the frequency band. Figure 10(a) is frequency spectrum corresponding to stable turning. It can be seen that when the cutting is stable, the spindle rotation frequency $\left(f_{s p}=9.2 \mathrm{~Hz}\right)$ is the dominant mode of vibration. This frequency is corresponding to rotation of spindle speed $(550 \mathrm{rpm}=9.2 \mathrm{~Hz})$. It is the nature of the stable cutting that the vibration would be dominant in the spindle rotation frequency and its harmonics. When the axial cutting depth was increasing with slight chatter operation, chatter frequency $f_{c}=49 \mathrm{~Hz}$ appears together with $f_{s p}$ as shown in Figure 10(b). When the operation is severe chatter as shown in Figure 10(c), the chatter amplitude increases with the largest amplitude at the same chatter frequency and $f_{s p}$ disappears in this case. Chatter caused by regenerative vibration always occurs at chatter frequency $f_{c}$ that is close to the natural frequency of the vibration system because this frequency is the weakest point in the observed system. The natural frequencies of the observed system have been measured by hammering tests and provided the natural frequency $f_{n} 54$ and $55 \mathrm{~Hz}$. Therefore, the chatter frequency was confirmed. These results also showed that FFT is able to detect chatter frequency in turning process, however the drawback of FFT is that it cannot show the time whenever the chatter vibration was occurring. 

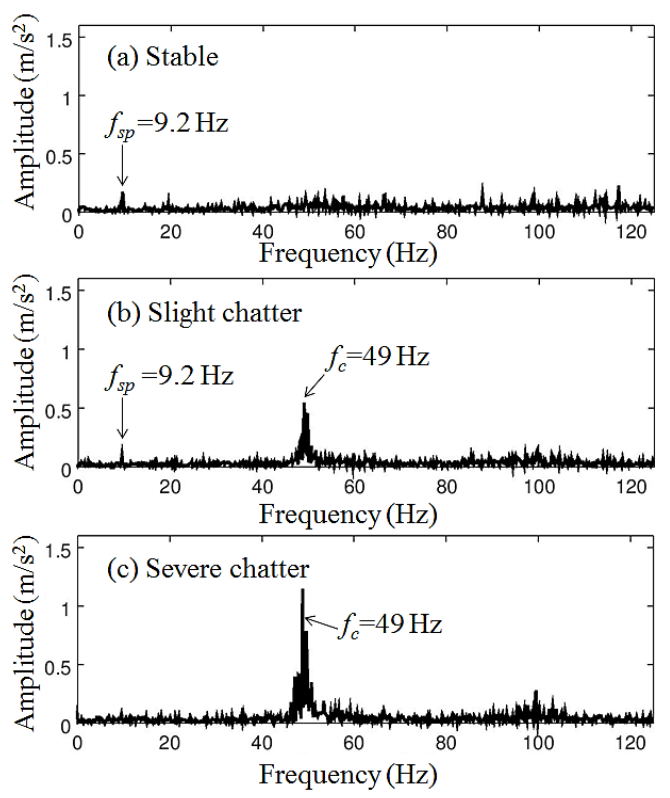

Figure 10. Frequency spectra for three kinds of machining states.

\section{Vibration Analysis using HHT and STFT}

The first step of HHT is applying EMD process to decompose raw signal to be a set of IMF components and the results are shown in Figure 11. Figure 11(a) and (b) are IMF components for stable and severe chatter vibrations, which correspond to signals in Figures 8(a) and 8(c), respectively. Eight IMF components and a monotonic-residue were obtained for these cases. As can be seen from the figures, each IMF component contains different oscillation and amplitude. For example, the first IMF $c_{1}$ contains the most oscillations. Otherwise, the last IMF $c_{8}$ contains the least oscillations. Therefore, $c_{1}$ contains the highest frequency and $c_{8}$ contains the lowest frequency among all IMFs.
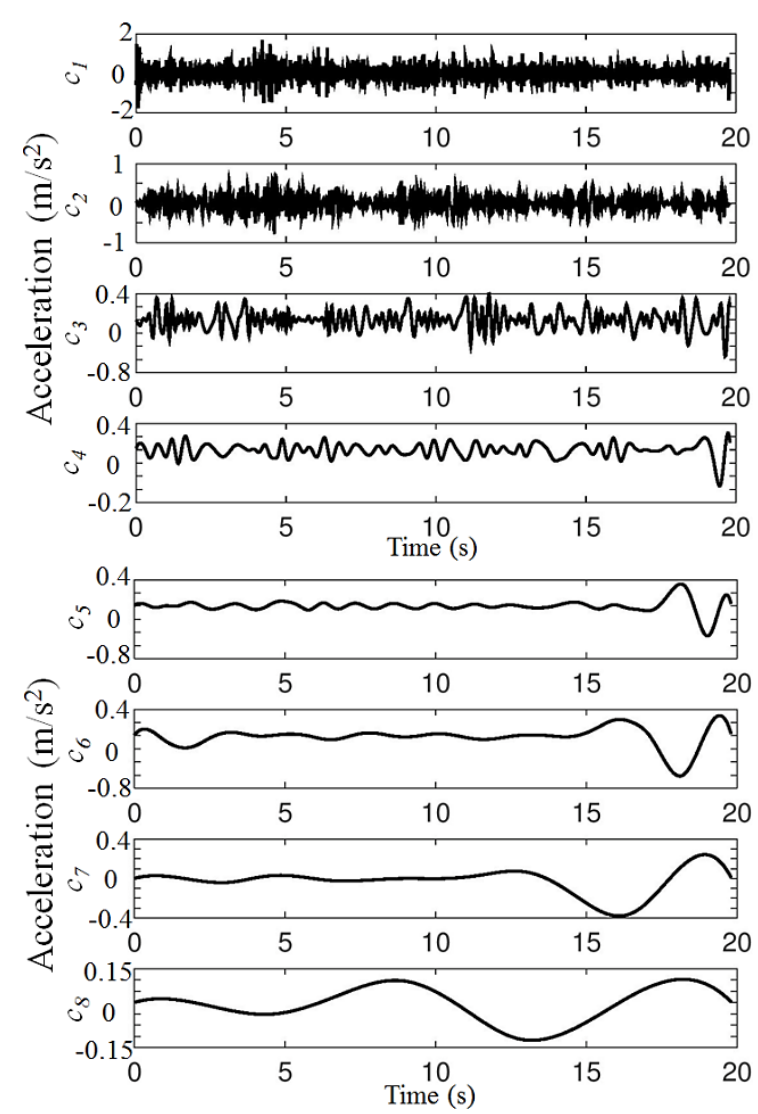

(a) IMF components for stable cutting
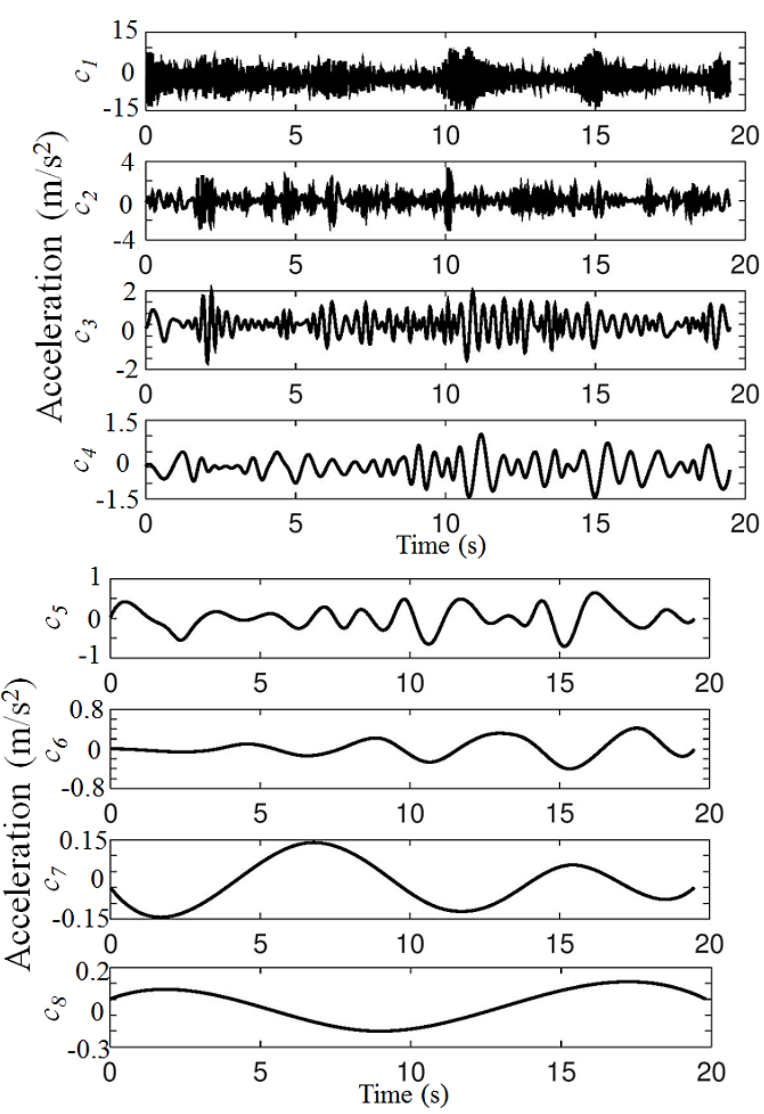

(b) IMF components for severe chatter

Figure 11. IMF components in time-domain obtained by EMD process. 
Next, the frequency content of the IMFs needs to be observed, and it was done by examined the first - fourth IMF components in Figure 11 using FFT to observe frequency content of each IMF, and the results are shown in Figure 12. All the symbols in these figures denoted the same as in Figure 10.

Every characteristic frequency appears in particular IMF of Figure 12 with different amplitude. The interesting thing is that each unique frequency is contained in the IMF component, which means that the sifting process by EMD decomposed the complex vibration into simple components. Figure 12(a) is IMFs in frequency-domain for stable cutting. Here, the first IMF $c_{1}$ just contains rotational spindle frequency. Besides, Figure 12(b) that is associated with severe chatter, the first IMF $c_{1}$ and the forth IMF include the chatter and a rotational spindle frequencies at $f_{c}=49 \mathrm{~Hz}$ and $f_{s p}=$ $9.2 \mathrm{~Hz}$, respectively.

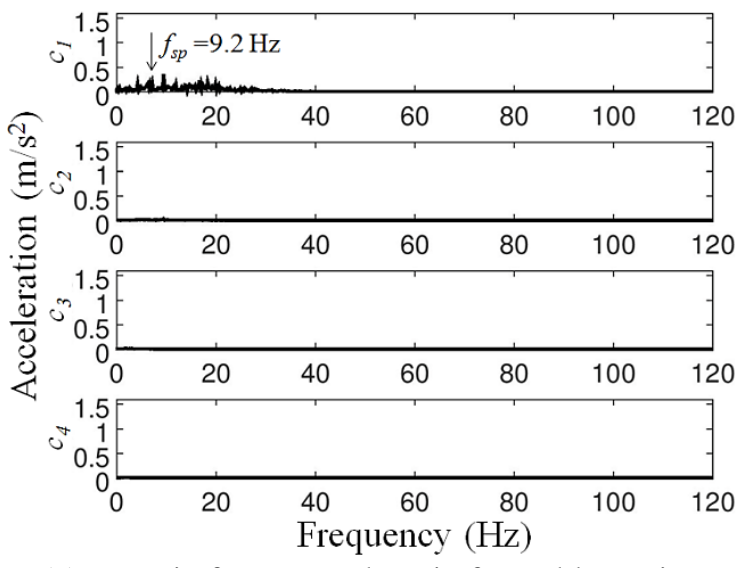

(a) IMFs in frequency domain for stable cutting

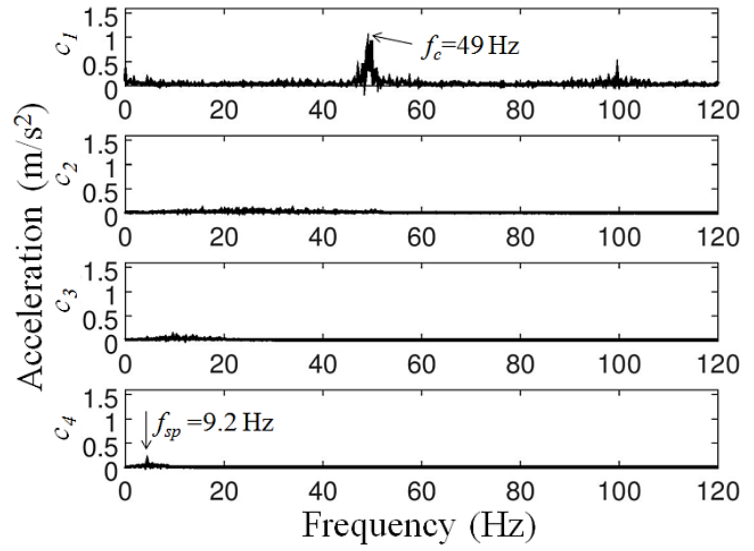

(b) IMFs in frequency domain for severe chatter

Figure 12. IMFs in frequency-domain corresponding to IMFs in Figure 11.

Above results showed that the EMD process separated complex vibrations into simple components, and each one of them contained a unique vibration mode caused in machining. EMD also separated the chatter from the others. In our study, chatter vibration was isolated in the first IMF $c_{l}$ of Figure 12(b), while other IMFs are signal without chatter. Thus, IMFs obtained by EMD process made it easy for chatter identification when it was combined with FFT.

The second step of HHT is applying the Hilbert transform to all IMFs for generating energy-time-frequency distribution which is represented in HHT spectrum and the result shown in Figures 13(a)-(c). The HHT spectra were compared to STFT spectrum obtained by short time Fourier transform as shown in Figures 13(d)-(f). According to both HHT and STFT spectra, machining states can be monitored both in time and frequency domains for all cases.

Figures 13(a)-(c) are HHT spectra for stable, slight chatter and severe chatter. On the other hand, Figures 13(d)-(f) are STFT spectra. As shown in the figures, both HHT and STFT spectra show good correlation with raw signals. This leads the conclusion that they have the capability to capture the turning states among stable, slight chatter and severe chatter on acceleration signal obtained with different cutting depths. From visual investigation of Figures 13(a) and 13(d) for explaining stable cutting, the energy just appears in rotational spindle frequency $f_{s p}=9.2 \mathrm{~Hz}$ with lowest energy level. And the energy level was increasing when operation is in unstable operation and the chatter frequency $f_{c}$ appears as shown in Figures 13(b), 13(c), 13(e) and 13(f). However, STFT spectra provides blurry and blocked time-frequency spectra. It is because, the frequency resolution and time resolution of $X(n, k)=\sum_{m=-\infty}^{\infty} x[m] w(n-m) e^{-j \frac{2 \pi}{N} k m}$ [7] provide constant for both time

and frequency. Besides, the idea of STFT is that series of the conventional Fourier transforms of finite length time signal are evaluated by applying a windowing function to the original time signal. Therefore the blocked spectrum is displayed in STFT. Lamraoui et al. [25] and Uekita and Takaya [26] took the STFT of the vibration signal and found that the spectra cannot capture the localized aspect of the chatter and tool failure because the STFT provide blocked spectra and spread the information across the transformed signal.

Otherwise, HHT spectra shows a significant improvement of the frequency resolution making the frequency components easier to be identified. The HHT spectra obtained by HHT are clearer than STFT spectra. By comparing STFT spectra formula given $X(n, k)=\sum_{m=-\infty}^{\infty} x[m] w(n-m) e^{-j \frac{2 \pi}{N} k m}$ [7] and HHT spectra formula given $\left.x(t)=\sum_{j=1}^{N k} a_{j}(t) \exp \left(i \int \omega_{j}(t) d t\right)\right)$

[22], it can be observed that STFT is based on the sliding window. Besides, the HHT is self-adaptive and does not consider to much manual intervention and HHT does not involve the concept of frequency resolution or time resolution using the instantaneous frequency concept. Consequently, it can be obtained a uniform high resolution in the HHT spectrum with full time and frequency range and makes it suitable to be applied for machining process monitoring. 

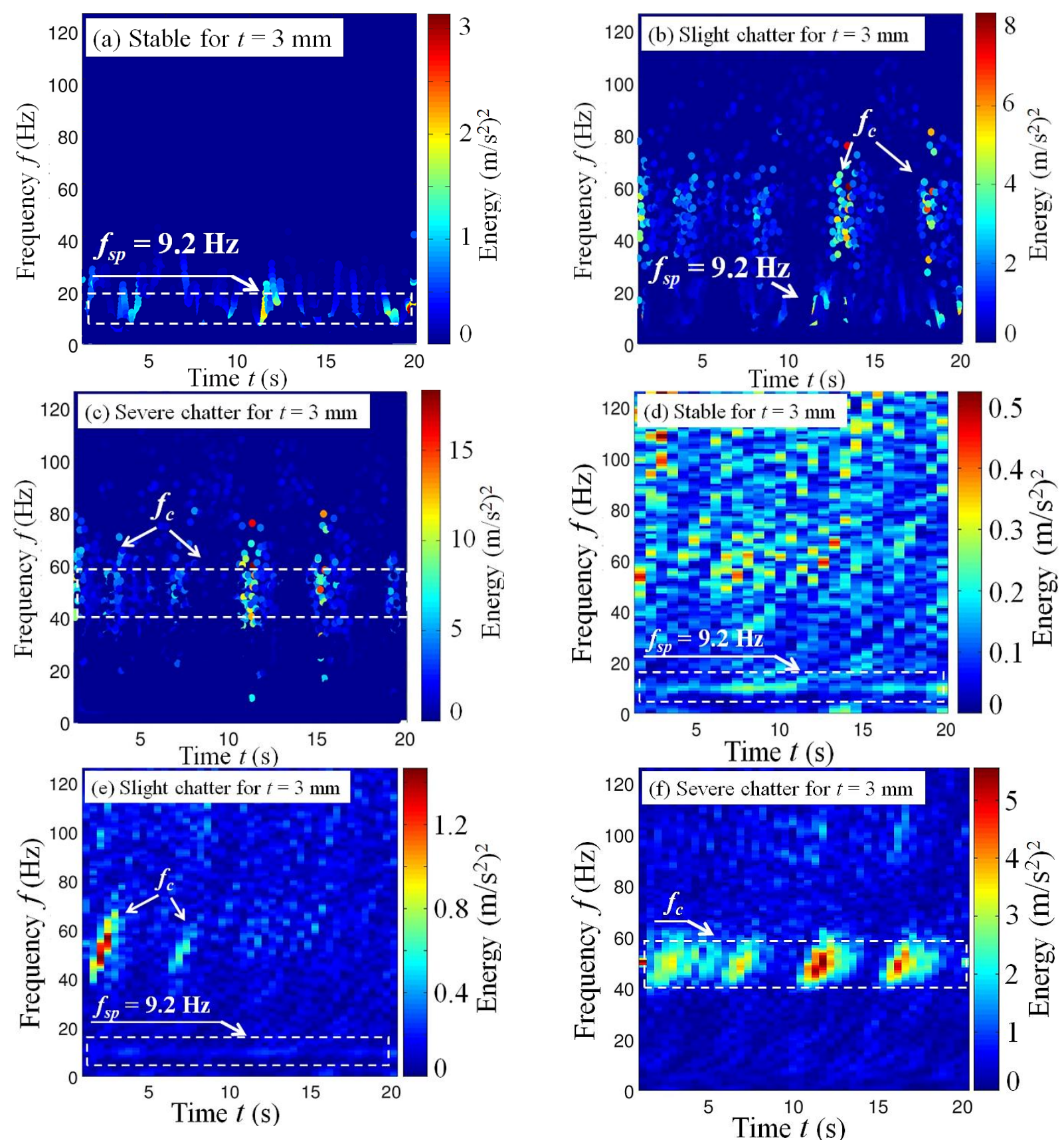

Figure 13. Turning process monitoring using HHT $(a, b, c)$ and STFT spectra $(\mathrm{d}, \mathrm{e}, \mathrm{f})$.

Therefore, HHT can improve energy-time-frequency spectrum and helps to correctly identify the characteristics of the cutting process. From these results, it might be said that HHT clearly shows an advantage over STFT by producing a better spectrum resolution.

\section{CONCLUSIONS}

This paper studied vibration analysis for chatter identification in turning process. Hilbert-Huang transform (HHT) was employed for analyzing vibrations and the result was compared to short time Fourier transform (STFT). Here are some important conclusions:

1. The empirical mode decomposition (EMD) process separated complex vibrations into simple components and each IMF contains physical meaning; containing one unique frequency.

2. The chatter was isolated in the first IMF from other signals, therefore EMD made it easy for chatter identification.

3. In spectrum analysis, HHT spectra showed its superiority over STFT spectra for chatter identification. When chatter occurs, the energy centralizes around the chatter vibration mode and HHT spectra provided high both time and frequency resolution.

4. STFT spectra was difficult to be used for chatter identification because it provided blurry and blocked spectra. 


\section{REFERENCES}

[1] N. Ambhore, D. Kamble, and S. Chinchanikar, "Analysis of tool vibration and surface roughness with tool wear progression in hard turning: An experimental and statistical approach," Journal of Mechanical Engineering and Sciences, vol. 14. pp. 64616472, 2020, doi: https://doi.org/10.15282/jmes.14.1.2020.21.0506.

[2] A. R. Yusoff, M.R.Z.M. Suffian, and M. Y. Thaib, "Literature review of optimization technique for chatter suppression in machining," Journal of Mechanical Engineering and Sciences, vol. 1. pp. 47-61, 2011.

[3] N. Jamil, A. R. Yusoff, and M. H. Mansor, "Literature review of electromagnetic actuator force generation for dynamic modal testing applications," Journal of Mechanical Engineering and Sciences, vol. 3. pp. 311-319, 2012, doi: http://dx.doi.org/10.15282/jmes.3.2012.7.0029.

[4] X. Dang, M. Wan, Y. Yang, and W. Zhang, "Efficient prediction of varying dynamic characteristics in thin-wall milling using freedom and mode reduction methods," Int. J. Mech. Sci., vol. 150, no. September 2018, pp. 202-216, 2019, doi: 10.1016/j.ijmecsci.2018.10.009.

[5] N. A. Kasim, M. Z. Nuawi, J. A. Ghani, M. Rizal, M. A. F. Ahmad, C. H. Che Haron, "Cutting tool wear progression index via signal element variance," Journal of Mechanical Engineering and Sciences, vol. 13. pp. 4596-4612, 2019. doi: https://doi.org/10.15282/jmes.13.1.2019.17.0387.

[6] H. Ma, J. Wu, L. Yang, and Z. Xiong, "Active chatter suppression with displacement-only measurement in turning process," J. Sound Vib., vol. 401, pp. 255-267, 2017, doi: 10.1016/j.jsv.2017.05.009.

[7] H. Li and Y. Chen, Handbook of Manufacturing Engineering and Technology. Springer-Verlag London, 2014.

[8] K. Kolluru and D. Axinte, "Coupled interaction of dynamic responses of tool and workpiece in thin wall milling," J. Mater. Process. Technol., vol. 213, pp. 1565-1574, 2013, doi: 10.1016/j.jmatprotec.2013.03.018.

[9] Y. Yamada, T. Kadota, S. Sakata, J. Tachibana, and Y. Kakinuma, "Integrated chatter monitoring based on sensorless cutting force/torque estimation in parallel turning," Int. J. Autom. Technol., vol. 11, no. 2, pp. 215-225, 2017, doi: 10.20965/ijat.2017.p0215.

[10] I. N. Tansel, X. Wang, P. Chen, A. Yenilmez, and B. Ozcelik, "Transformations in machining. Part 2. Evaluation of machining quality and detection of chatter in turning by using s-transformation," Int. J. Mach. Tools Manuf., vol. 46, pp. 43-50, 2006, doi: 10.1016/j.ijmachtools.2005.04.011.

[11] J. Xu, K. Yamada, K. Seikiya, R. Tanaka, and Y. Yamane, "Effect of different features to drill-wear prediction with back propagation neural network," Precis. Eng., vol. 38, pp. 791-798, 2014, doi: 10.1016/j.precisioneng.2014.04.007.

[12] S. Gu, J. Ni, and J. Yuan, "Non-stationary signal analysis and transient machining process condition monitoring," Int. J. Mach. Tools Manuf., vol. 42, pp. 41-51, 2002, doi: 10.1016/S0890-6955(01)00097-9.

[13] H. Cao, K. Zhou, and X. Chen, "Chatter identification in end milling process based on EEMD and nonlinear dimensionless indicators,” Int. J. Mach. Tools Manuf., vol. 92, pp. 52-59, 2015, doi: 10.1016/j.ijmachtools.2015.03.002.

[14] T. Kalvoda and Y. R. Hwang, "Analysis of signals for monitoring of nonlinear and non-stationary machining processes," Sensors Actuators, A Phys., vol. 161, no. 1-2, pp. 39-45, 2010, doi: 10.1016/j.sna.2010.05.032.

[15] R. Teti, K. Jemielniak, G. O'Donnell, and D. Dornfeld, “Advanced monitoring of machining operations," CIRP Ann. - Manuf. Technol., vol. 59, no. 2, pp. 717-739, 2010, doi: 10.1016/j.cirp.2010.05.010.

[16] A. Susanto, C.-H. Liu, K. Yamada, Y.-R. Hwang, R. Tanaka, and K. Sekiya, "Milling process monitoring based on vibration analysis using Hilbert-Huang transform,” Int. J. Autom. Technol., vol. 12, pp. 688-698, 2018, doi: 10.20965/ijat.2018.p0688.

[17] A. Susanto, C. H. Liu, K. Yamada, Y. R. Hwang, R. Tanaka, and K. Sekiya, “Application of Hilbert-Huang transform for vibration signal analysis in end-milling,” Precis. Eng., vol. 53, pp. 263-277, 2018, doi: 10.1016/j.precisioneng.2018.04.008.

[18] A. Susanto, K. Yamada, K. Mani, R. Tanaka, and K. Sekiya, "Vibration analysis in milling of thin-walled workpieces using Hilbert-Huang transform," in International Conference on Leading Edge Manufacturing in 21st century (LEM21), 2017, doi: 10.1299/jsmelem.2017.9.031.

[19] W. Soong, "Hilbert-Huang Transform-Based Emitted Sound Signal Analysis for Tool Flank Wear Monitoring," no. March 2017, 2013, doi: 10.1007/s13369-013-0580-7.

[20] P. Wolszczak, G. Litak, and M. Dziuba, "Monitoring of drilling conditions using the Hilbert-Huang transformation," in Matec web of Conferences, 2018, vol. 148, doi: 10.1051/matecconf/201814816003.

[21] Y. Altintas, Metal Cutting Mechanics, Machine Tool Vibrations, and CNC Design. Cambridge University Press, New York, 2012.

[22] N. E. Huang and S. S. P. Shen, Hilbert-Huang Transform and Its Applications. World Scientific, 2005.

[23] G. Zhao, L. Liu, D. Wang, J. Guo, and W. Chen, "Mechanical Properties of AISI 1045 Steel Subjected to Combined Loads of Tension and Torsion," Exp. Tech., vol. 42, no. 4, pp. 393-406, 2018, doi: https://doi.org/10.1007/s40799-018-0236-3.

[24] T. L. Schmitz and K. S. Smith, Machining dynamics: Frequency response to improved productivity. Springer US, 2009.

[25] M. E. B. M. Lamraoui, M. Thomas, "Cyclostationarity approach for monitoring chatter and tool wear in high speed milling," Mech. Syst. Signal Process., vol. 44, 2014, doi: 10.1115/1.1308035.

[26] M. Uekita and Y. Takaya, "Tool condition monitoring technique for deep-hole drilling of large components based on chatter identification in time-frequency domain," Measurement, vol. 103, pp. 199-207, 2017, doi: 10.1016/j.measurement.2017.02.035. 